\title{
Paideias decoloniales: ensayos de formación en la literatura franco-antillana
}

\author{
Decolonial Paideias: essays of formation in
}

Franco-Antillean Literature

Florencia Bonfiglio

IDIHCS, UNLP-CONICET, La Plata, Argentina

flobonfiglio@hotmail.com

Resumen: Esta investigación indaga en dos textos clave de la ensayística franco-antillana del siglo XX que comparten una función formativa y un objetivo común de concientización racial y social. Luego de una reflexión sobre los conceptos de cultura y colonialismo, abordaremos el clásico ensayo del etnólogo haitiano Jean Price-Mars Así habló el tío (1928), como un antecedente de Piel negra, máscaras blancas (1952) del psiquiatra martiniqueño Frantz Fanon. Ambos constituyen "ensayos de formación" descolonizadores en los que diversas matrices discursivas -la investigación etnográfica, el psicoanálisis-, relacionadas con las diferentes proveniencias disciplinares de sus autores, son moduladas por una función pedagógica determinante y el predominio de patrones narrativos como el moderno relato de formación o Bildungsroman. Leídos como paideias decoloniales, ambos ensayos plantean la urgencia de una educación opuesta a la "asimilación" francesa, que implica un desaprendizaje de las ideas, creencias y valores hegemónicos "blancos". Como veremos, el desarrollo de un programa formativo descolonizador es profundizado por Fanon de modo radical en cuanto no solo denuncia, como lo hiciera Price-Mars, la alienación de aquellos sujetos de 
piel negra que adoptan máscaras blancas, sino que alerta también respecto de la mística y reivindicativa négritude que cae de modo involuntario en las trampas del colonialismo.

Palabras clave: Price-Mars, Fanon, ensayo antillano, descolonización.

Авstract: The paper examines two key essays from the 20th century French Caribbean which share a formative function and a common purpose of raising racial and social awareness. After a reflection on the concepts of culture and colonialism, we will look at the classic So spoke the uncle (1928) by Haitian ethnologist Jean Price-Mars as an antecedent of Black Skin, White Masks (1952) by Martinican psychiatrist Frantz Fanon. Both constitute decolonizing "essays of formation" in which diverse discursive formats -ethnographic research, psychoanalysis-, linked with the authors' different disciplinary origins, are modulated by a decisive pedagogical function and the predominance of narrative patterns such as the modern novel of formation or Bildungsroman. Read as decolonial lessons, both essays express the urgent need for an education opposed to French "assimilation", which implies a de-learning of "White" hegemonic ideas, beliefs, and values. As we will see, the development of a decolonizing formative program is furthered by Fanon in a radical way since he not only denounces, as Price-Mars had previously done, the alienation of those who possess black skin and adopt white masks; he also warns against the mystic and enthusiastic négritude which unwillingly falls into the trap of colonialism.

Keywords: Price-Mars, Fanon, Antillean essay, decolonization.

\section{A MODO DE INTRODUCCIÓN: CULTURA Y COLONIALISMO REVISITADOS}

Los términos "colonia" y "cultura" provienen del mismo verbo latino colere, con los diversos significados de "cultivar", "habitar", "proteger", "honrar con adoración”. Raymond Williams, en su clásico libro Keywords (1983), analiza con detenimiento el segundo término, el concepto moderno de cultura, por su particular complejidad en la lengua inglesa -atribuible en parte a su intrincado desarrollo histórico en las lenguas europeas, según explica-, y, como cabe suponer, por su relevancia particular, en cuanto su adjetivo distingue a los propios estudios culturales. Pero resulta sin dudas llamativo que, mencionado entre las demás derivaciones del 
verbo latino, el vocablo "colonia" quede inexplorado, y totalmente fuera del compendio de "palabras clave". El sustantivo, en efecto - consigna Williams-, deriva de colere en el sentido de habitar: "Colonia" es el territorio habitado por Colonus -que es, pues, labrador/cultivador y también habitante-. Asimismo, el otro significado del verbo, "honrar/adorar", nos lleva a cultus (culto). Según advierte el propio Williams, los sustantivos derivados -luego bien distintos- de colere (colonia, colono, cultura, culto) pueden presentar "ocasionales solapamientos" $(87)^{1}$. En esta ocasión, me interesa detenerme a reflexionar, más bien, en las bifurcaciones, en la lógica dicotómica excluyente característica del binarismo occidental.

Aunque Williams no incorpore "colonia" a su lexicón de palabras clave, sí incluye la entrada de "imperialismo" que, como bien especifica, en el sentido moderno se desarrolló de modo primordial en inglés luego de 1870. Ligadas también al proceso expansionista europeo, las voces espańolas derivadas de "colonia" -como el adjetivo "colonial"- registran usos a partir de 1843; el verbo "colonizar" se encuentra con las siguientes acepciones: 1) "convertir [un país] en colonia"; 2) "convertir en colonia un territorio inculto y deshabitado"; 3) "formar o establecer colonia [en un lugar, especialmente en un ser vivo o en una parte de él]"2. En la segunda definición mencionada, ya claramente ideologizada, colonizar supone la ausencia de cultura del país colonial: "territorio inculto y deshabitado" (Segura 97) es casi un oxímoron o contradictio in terminis -¿un territorio verdaderamente deshabitado no volvería impropia la adjetivación "culto"/“inculto"?-. La definición, sin embargo, hace juego con la doctrina del vacuum domicilium o el conocido mito imperial del continente vacío o desierto; su deconstrucción expone, pues, la violencia simbólica del colonialismo. No parece casual por lo tanto que, luego de la expansión del sentido figurado de cultura como

1 Cito del original, de la entrada de "Culture" en Keywords. A Vocabulary of Culture and Society: "The fw is cultura, L(atin), from rw colere, L. Colere had a range of meanings: inhabit, cultivate, protect, honor with worship. Some of these meanings eventually separated, though still with occasional overlapping, in the derived nouns. Thus 'inhabit developed through colonus, L to colony. 'Honor with worship' developed through cultus, L to cult. Cultura took on the main meaning of cultivation or tending, including, as in Cicero, cultura animi, though with subsidiary medieval meanings of honor and worship" (Williams 87).

2 Sigo las acepciones del verbo (en la entrada de "Colonia"), aportadas por Santiago Segura Munguía en su Lexicón [incompleto] etimológico y semántico del Latín y de las voces actuales que proceden de raices latinas o griegas (97). 
"cultivo del espíritu" a partir del Siglo de las Luces, y en especial desde mediados del siglo XIX, mientras el concepto moderno se consolida en Europa, las colonias como territorios "sin cultura" y a cultivar se afiancen en el imaginario eurocéntrico sobre los países de ultramar. Desde entonces, y en concordancia con la filosofía de la historia hegeliana, el espíritu se cultiva en Europa y los productos agrícolas en las colonias. Cultura y colonia, vistos con ojos imperiales, resultan opuestos, cuando no contradictorios, en el imaginario europeo, impuesto y exportado, a su vez, a las colonias ${ }^{3}$. Hacia fines del siglo XIX en el Río de la Plata, para el emigrado francés Paul Groussac (1848-1929), autoridad intelectual indiscutible en la francófila Argentina, existía incluso un verdadero abismo entre los que en su libro de viajes Del Plata al Niágara (1897) llamaba "remolcadores y remolcados, entre pueblos productores y pueblos consumidores de civilización” (XXIII); entre, a su vez, los franceses -blancos como él-y quienes, avanzado su viaje, denominaba irónicamente sus "compatriotas" -negros- de la Martinica y la Guadalupe (143):

Al paso que se va conquistando el planeta, se dilatan más y más los territorios de la colonización y adaptación europea, que se tornan mercados útiles o debouchés de la vieja productora exuberante. Son países civilizados -por ella-que fácilmente llegan a poseer, en cambio de su suelo virgen, todos los instrumentos de la civilización, desde el buque traficante hasta el libro iniciador, en un todo iguales a los de allá: la única diferencia, más profunda aun para el libro que para el buque, está en que los civilizados compran lo que los civilizadores elaboran... (Groussac XXIII).

3 Esto, como sostengo, es válido aun considerando los sentidos más modernos adoptados por el vocablo "culture"/cultura, como bien consigna Williams, a partir de su uso en plural impulsado por Herder en el contexto del Romanticismo alemán, como alternativa de civilización (para definir culturas variables y específicas -folk, tradicionales, regionales, nacionales, populares, etcétera-, designando los modos particulares de vida de un pueblo, grupo, período, etcétera), uso luego adoptado por G. F. Klemm para establecer el sentido que se volvería dominante en las modernas ciencias sociales (Williams 89-90). Desde entonces, por ejemplo, se vuelven conceptualizables "culturas primitivas" en el campo de la antropología, mientras estas mismas, con ojos imperiales, son consideradas propias de aquellos "territorios incultos" a colonizar. 
Si desde tal concepción etnocéntrica colonizar implica exportar cultura europea, puesto que ninguna otra existiría o se produciría en las colonias, el proceso de descolonizar en el siglo XX será entendido como el de librarse de una cultura impuesta, quitarse un espíritu ajeno: desalienarse. La contigüidad entre descolonización y desalienación será explicitada por pensadores ineludibles del siglo XX, como el psiquiatra antillano Frantz Fanon, quien, junto con la necesidad de una revolución política que condujera a las independencias de los países coloniales, subrayó la urgencia de una descolonización mental, individual y colectiva. "Liberar al hombre de color de sí mismo" (8) es el objetivo de Fanon en Piel negra, máscaras blancas, pues es la construcción del "negro" -incluso la bienintencionada invención del "alma negra"-, vale decir, el mito racial expandido por la cultura europea, el que ha colonizado a los afrodescendientes. En este sentido, si por un lado el psiquiatra martiniqueño se muestra heredero del ideario descolonizador de la negritud de su maestro Aimé Césaire, y lee el fenómeno de la (des)alienación a través del particular problema de la Asimilación en las Antillas colonizadas por Francia ${ }^{4}$, tal como lo hicieran sus antecesores del Caribe francófono desde los años veinte, especialmente en la independiente Haití; por otro lado, Fanon da un paso más y denuncia la trampa misma que la negritud encierra.

Quizá sea necesario recuperar aquí las condiciones de posibilidad de los planteos más lúcidos de Fanon, remontándonos a los inicios de la discusión sobre la "asimilación" en el campo intelectual negro y francófono del periodo de entreguerras, estableciendo una línea de continuidad entre aquellos precursores haitianos como Jean Price-Mars, que reaccionaron contra la imposición de parámetros occidentales -eurocéntricos y negrófobos-, reivindicando el "indigenismo" afrodescendiente, y la "negritud" posterior de Aimé Césaire como discurso formador del

4 La asimilación fue la base ideológica de la política colonial francesa desde el siglo XIX. Implicó la expansión de la cultura y las costumbres francesas a las colonias, así como la adopción de los derechos y obligaciones de la ciudadanía francesa. Sus inicios se situaron durante la Revolución de 1789. Luego, a comienzos del siglo XIX, Napoleón Bonaparte rechazó la universalidad de las leyes y declaró que las colonias serían gobernadas de modo separado, hasta que con la Revolución de 1848 la Asimilación fue restaurada. 
ideario fanoneano, que emergerá con fuerza a la par del proceso de descolonización posterior a la Segunda Guerra Mundial. Entre estos corpus de ideas mediaron, por cierto, unos pocos ańos, algunas figuras clave, y revistas como la Revue du Monde Noir, Légitime Défense y L'Étudiant noir, órganos de difusión de la cultura afroantillana en París que, aunque efímeros, marcaron el camino a seguir.

La primera publicación, bilingüe, La Revue du Monde Noir. The Review of the Black New World -con seis números publicados entre noviembre de 1931 y junio de 1932-, fue sin duda central para la constitución de una red de escritores negros de diversas procedencias y a la formación de un campo intelectual afroantillano en París. Fundada por el haitiano Leo Sajous y las hermanas martiniqueñas Jane y Paulette Nardal ${ }^{5}$, la revista se afilió con el entonces influyente Renacimiento de Harlem y convocó al núcleo de afroantillanos ya participantes del salón literario de las Nardal -Jean Price-Mars y René Maran entre los más reconocidos- alrededor de un proyecto centrado en lo cultural, con una postura más bien conciliadora respecto de Francia ${ }^{6}$. Como bien sintetiza el crítico Buata Malela, la revista consideraba la colonización "como un contacto de cultura al contrario de lo que sostendrá Aimé Césaire en los años cincuenta” (120)7.

5 Paulette Nardal era la primera martiniqueña afrodescendiente en estudiar en una universidad francesa (estudió Inglés, en la Sorbona). Una tercera hermana (de las siete Nardal), Andrée, también colaboró en la Revue du Monde Noir. Cabe agregar que la revista aprovechó a su vez el impulso dado por La Dépêche Africaine (1928-1932), órgano del Comité de Défense des Intérêts de la Race Noire (CDIRN) dirigido por el guadalupeño Maurice Satineau y relacionado con el garveyismo, y donde Jane y Paulette Nardal habían participado. Para el importante rol de las hermanas Nardal en la constitución de redes intelectuales negras, así como su posición "afrolatina" y moderada, que se distinguía de la estridencia del panafricanismo garveísta, remito a Sharpley Whiting (17).

6 Participaron en la Revue du Monde Noir figuras centrales de Harlem como Langston Hughes y el jamaiquino Claude McKay, aunque la mayoría de los que escribieron fueron antillanos de habla francesa: además de Maran (ganador del Premio Goncourt en 1921 por Batouala. Véritable roman nègre), otros martiniqueños como Louis Thomas Achille (primo de las Nardal), Gilbert Gratiant y algunos de los jóvenes que fundarían Légitime Défense; haitianos como Price-Mars y Carl Brouard (más tarde director de la revista haitiana Les Griots) y guyaneses como Félix Éboué.

7 Como explica Malela, la revista diseńaba una especie de "identidad triangular" (origen antillano, África y Francia), y se inventaba "una identidad franco-antillana 
Sería, por el contrario, la segunda revista mencionada, Légitime Défense (único número de 1932), lanzada por los jóvenes estudiantes martiniqueños Jules-Marcel Monnerot -hijo del socialista Jules Monnerot-, René Ménil y Étienne Léro, la que adquiriría, con el empuje del surrealismo metropolitano y el ideario socialista, la revista adquiriría un claro sesgo político y revolucionario, materializado en un discurso fuertemente antiasimilacionista y anticolonialista, germen ya de la "negritud", enunciada con ese nombre desafiante tres años después en la también efímera pero seminal revista L'Étudiant noir (¿5? números, 1935), órgano de los estudiantes martiniqueños en París, dirigida por Aimé Césaire. Césaire, tan disidente como el grupo de Légitime Défense, será sin duda el eslabón clave entre las primeras reivindicaciones de la identidad afrodescendiente en las Antillas, acompañadas de las denuncias de la "asimilación" francesa y el discurso más revolucionario de Fanon, su discípulo en Fort-de-France una vez cumplido el "retorno a la tierra natal" desde París en 1939. Ya en el primer número de L'Étudiant noir, bajo el título de "Juventud negra y asimilación", el joven Césaire se perfila como el portavoz de una paideia liberadora:

La tribu de los Viejos dice: “asimilación”, nosotros respondemos: “iresurrección!”. [...]

Pero para ser uno mismo, hay que luchar; primero contra los hermanos enajenados que tienen miedo de ser ellos mismos; es la turba senil de los asimilados.

Luego contra aquellos que quieren extender su yo; es la legión feroz de los asimiladores.

En fin, para ser uno mismo, hay que luchar contra uno mismo (101-102).

Césaire, como recordara en tantas entrevistas, descubre en París no solo el África a través de su amigo L. S. Senghor y la biblioteca africanista europea, sino también la serie de discursos emancipatorios que lo condujeron a la proclamación de la negritud, desde el "Black is

mediante la referencia al África, ya que toda movilización del pasado antillano anterior a 1848 reenviaría a la trata negrera y la esclavitud" (120). El rescate del "alma negra" se insertaba, de hecho, en la lógica del campo parisino, respondía a la búsqueda de autorización en la representación más "auténtica" de lo africano. La revista se afiliaba especialmente con la postura conciliadora y francófila de René Maran, que otorgaba a Francia el rol de guía (Malela 120). 
beautiful" del Renacimiento de Harlem al movimiento "indigenista" haitiano, ambos hasta entonces totalmente desconocidos en la Martinica.

En efecto, la deconstrucción de la "asimilación" en cuanto proceso enajenante era ya elaborada por el haitiano Jean Price-Mars en sus fundadores "ensayos de etnografía", Asi habló el tío (1928), donde "la facultad de atribuirse una sociedad otra cosa que ella no es" era denominada lúcidamente como "bovarismo colectivo" y denunciada en clave política, en el contexto de la ocupación estadounidense de Haití, como un grave peligro nacional. Price-Mars comenzaba aludiendo en el prefacio a la debilidad de los revolucionarios haitianos que "al día siguiente de 1804" solo habían copiado "el único modelo que se ofrecía a su inteligencia" (XXXIV) -el modelo francés-, actitud imitativa que ahora parecía replicarse ante el avance norteamericano. Para el etnólogo, era precisamente el desprecio del "negro", el olvido del haitiano de su raíz africana y la suplantación de la cultura indígena por la cultura blanca europea lo que explicaba el sometimiento de Haití:

[N] uestra manera de utilizar las leyes de la imitación para tratar de darnos un alma a préstamo, la desviación patológica que hemos infligido al bovarismo de las colectividades concibiéndonos otros que no somos, la incertidumbre trágica que tal tentativa imprime a nuestra evolución en el momento en que los imperialismos de toda laya enmascaran sus apetencias bajo apariencias de filantropía (Price-Mars XXXVII).

Si la reivindicación por parte de Price-Mars de la cultura haitiana de raíz africana se mostraba como una necesaria resistencia frente al imperialismo estadounidense, y de allí su importancia para el contemporáneo indigenismo local -en torno de la reconocida Revue Indigène-, al mismo tiempo su crítica del racismo internalizado entre los mismos afrodescendientes funciona sin duda como un discurso modélico para el movimiento francófono de la negritud en el "Caribe parisino", como lo llama Malela (8). Así, ciertas diatribas contra la negrofobia y la denuncia de las desviaciones patológicas de aquel "nosotros" afroantillano que reconoce que "nuestra vanidad solo se satisface cuando anotamos las frases escritas por otros donde se glorifica a 'Los Galos nuestros abuelos”' (Price-Mars 273) serán retomadas 
por quienes -como el grupo de Légitime Défense, Aimé Césaire, L. G. Damas y luego Fanon- lucharán contra la "asimilación" y el complejo de inferioridad de los negros colonizados por Francia. Todos ellos comparten, como lamenta Price-Mars, la pertenencia a sociedades alienadas de sí mismas, donde "el hombre más distinguido [...] prefiere que se le encuentre algún parecido con un esquimal, un samoyedo o un tunguso con tal de que no se le recuerde su ascendencia guineana o sudanesa" (XXXV).

Sin embargo, el esfuerzo de Price-Mars por enaltecer la cultura africana -su esfuerzo por visibilizar una civilización negra-acusa la primacía del patrón axiológico europeo, toda vez que, a través de su método de etnografía comparada, intenta encontrar "gloriosos parentescos" entre las fábulas africanas y las europeas (Price-Mars 11), o bien apela a la historia de las religiones para legitimar, desde un enfoque evolucionista, las prácticas del vudú en cuanto actos de misticismo comunes a todos los cultos primitivos (Price-Mars 43-44) ${ }^{8}$. Las operaciones del etnólogo conducirán, al fin y al cabo, a una reivindicación del "alma negra" en cuanto mentalidad "primitiva"/"mística" y a un rescate de la "emotividad" frente a la racionalidad occidental que, como sabemos, serán luego deconstruidos por críticos de la negritud -y de sus usos racistas-, tales como René Depestre en la misma tradición haitiana ${ }^{9}$. Aun así, no obstante la demanda de superación de tales paradigmas esencialistas, fue el mismo Depestre quien destacó el valor ejemplar del libro de su antecesor Price-Mars, en cuanto "primer inventario coherente de la herencia africana en Haití":

[Ll] egaba en el momento en que los jóvenes haitianos que entonces tenían talento sentían, bajo la odiosa ocupación extranjera, la necesidad de romper definitivamente con la imitación estéril de las corrientes estéticas importadas de París

8 Para profundizar en la adopción del pensamiento positivista y evolucionista en Price-Mars remito a Novau, quien observa que el etnólogo haitiano "prolonga algunos conceptos respecto de la africanidad propios del legado de ideas positivistas y etnocéntricas de entresiglos" (4).

9 Véase, sin ir más lejos, el prólogo de Depestre a la traducción de Así habló el tio de Casa de las Américas, en la edición que aquí citamos; o el más conocido ensayo de Depestre, Buenos días y adiós a la negritud, también traducido por Casa de las Américas en 1986. 
y de correr los riesgos y peligros de la gran aventura de una literatura y de un arte estrechamente articulados a las realidades y a los sueńos de Haití (XII-XIII).

Asimismo, la importancia del legado del etnólogo haitiano para el "mundo negro" había sido establecida en los años cincuenta, cuando Price-Mars fuera elegido de modo unánime para presidir el Primer Congreso Internacional de Escritores y Artistas Negros, celebrado en La Sorbona en 1956, y deviniera, a continuación, el primer presidente de la Sociedad Africana de Cultura - una institución cuyos supuestos serían cuestionados, empero, por el más revolucionario Frantz Fanon en su comunicación al Segundo Congreso de Escritores y Artistas Negros (Roma, 1959), y luego publicada en Los condenados de la tierra $(1961)^{10}$.

En efecto, en el contexto de la descolonización iniciada luego de la Segunda Guerra Mundial, el joven Frantz Fanon no solo denuncia -como lo hiciera Price-Mars-, la alienación de aquellos sujetos de piel negra que adoptan máscaras blancas; alerta además respecto de la cultura blanca que ha impuesto sus parámetros etnocéntricos incluso entre aquellos "negros contemporáneos" que luchan contra el racismo: "cueste lo que cueste, hay que probar al mundo blanco la existencia de una civilización negra" (28), desliza con ironía Fanon ya en su primer ensayo de 1952, Piel negra, máscaras blancas. Es esta cultura alienante la que ha alimentado a la mística negritud, pues los secularizados europeos, una vez reconocida la existencia de una "civilización africana" -como advierte el intelectual antillano-, han terminado por conceder a los negros un mundo esencial, espiritual, que ellos perdieran por exceso de racionalismo -de allí el auge del negrismo y de las "culturas primitivas" para las vanguardias artísticas-, mientras conservan los cultivos coloniales: el "mundo objetivo de las tierras, los bananos y las heveas" (Fanon 106), vale decir, la cultura material.

Price-Mars tuvo a cargo la conferencia inaugural y presidió también el Segundo Congreso de Roma. En ambos participaron tanto Césaire como Fanon, cuya conferencia en 1959, luego publicada como "Sobre la cultura nacional" en Los condenados de la tierra, se tituló: "El líder político considerado como el representante de una cultura”. 


\section{LA DESCOLONIZACIÓN COMO DESALIENACIÓN Y DESAPRENDIZAJE}

Contemporáneamente, en la misma línea de Fanon -quien, lejos de los esencialismos de la negritud, entiende que la descolonización implica deconstruir el racismo como una "epidermización de la inferioridad funcional a la dominación económica" (10) - y a partir de un verso de Derek Walcott, el barbadense George Lamming propone la imagen de la colonización como el proceso de habitar la piel, establecer colonia en el mismo cuerpo y mente del inferiorizado, evocando aquella acepción más biológica del verbo "colonizar" - "formar o establecer colonia [en un lugar, especialmente en un ser vivo o en una parte de él]" (Segura 97)-. Frente a este fenómeno destituyente, el Bildungsroman de Lamming, En el castillo de mi piel (1953), intenta desde el mismo título restituir la soberanía alienada. La función formativa y descolonizadora de la escritura de Lamming es un elemento central desde el momento en que elige para su ficción autobiográfica el conocido patrón de la novela de aprendizaje ${ }^{11}$. En el caso que aquí me ocupa-el de Piel negra, máscaras blancas de Fanon-, o del comentado Así habló el tío de Price-Mars, es el ensayo -uno de los principales "géneros didácticos" de la modernidadla vía discursiva para el ejercicio terapéutico, siendo rectora su función formativa de alcance comunitario, que permite caracterizar a ambas escrituras como paideias decoloniales.

Piel negra, máscaras blancas se presenta, en efecto, como una paideia descolonizadora, y en tal sentido terapéutica en términos colectivos, en primer lugar porque el texto del psiquiatra martiniqueño -cuya especialidad disciplinar podría suponer el desarrollo de un discurso científico-deriva hacia una modalidad de intervención político-cultural. La operación, aunque más abiertamente militante, es por cierto similar a la de Price-Mars en Así habló el tío, pensado originalmente como conferencias de divulgación y atravesado por contenidos ético-formativos que exceden el marco de la etnografía, y que se vuelven bien evidentes en la conferencia publicada como postfacio:

Solo nos será dado ser nosotros mismos a condición de no

11 Trabajé este aspecto en una ponencia presentada en el último Congreso Internacional Orbis Tertius (Universidad de La Plata, 2019), a ser publicada en actas bajo el título: "Barbados, Little England, o el aprendizaje del despojo: En el castillo de mi piel de George Lamming”. 
repudiar ninguna parte de la herencia ancestral. Pues bien, esta herencia es en sus ocho décimas partes un don del África. [...] Blancos, negros, mulatos, "griffes", ochavones, cuarterones, morabitos, "sacatras", qué importan esas vanas etiquetas del expolio colonial si nos sentimos hombres resueltos a desempeñar a cabalidad nuestro papel de hombres sobre esta minúscula parte de la escena del mundo que es nuestra sociedad haitiana (Price-Mars 273-274).

En el caso de Piel negra, máscaras blancas, el comienzo de Fanon es decisivo: un epígrafe del Discurso sobre el colonialismo (1950) de Aimé Césaire que funciona como definición de la pedagogía racista y colonial -una "pedagogía de la crueldad" en los términos más actuales de Rita Segato" ${ }^{12}$ que el ensayo intentará destruir: "Yo hablo de millones de hombres a quienes sabiamente se les ha inculcado el miedo, el complejo de inferioridad, el temblar, la genuflexión, la desesperación, el servilismo" (Fanon 7). A renglón seguido, Fanon anuncia, con el lenguaje tanto auroral como hermético de los movimientos de vanguardia:

La explosión no tendrá lugar hoy. Es demasiado pronto... o demasiado tarde.

No vengo armado de verdades decisivas.

Mi conciencia no está transida de resplandores esenciales.

Sin embargo, con toda naturalidad, pienso que sería bueno decir unas cuantas cosas que vale la pena que sean dichas. [...] ¿Por qué escribir esta obra? Nadie me lo había pedido.

Sobre todo, no me la pidieron aquellos a los que va dirigida. ¿Entonces? Entonces, con calma, respondo que en la tierra hay demasiados imbéciles. Claro que una afirmación como esta hay que probarla.

Hacia un nuevo humanismo... (ibid.).

Lejos de sorprendernos, el comienzo de Fanon -nítido heredero del incendiario Rimbaud-, explica el hecho de que, sometido a la evaluación de su director de tesis doctoral en Lyon con el título "Ensayo sobre la desalienación del negro", el manuscrito de Piel negra, máscaras blancas

12 Sigo las definiciones de Segato sobre la normalización del poder masculino y su mandato patriarcal (misógino, homofóbico y racista a la vez) como una "pedagogía de la crueldad, funcional a la codicia expropiadora" que caracteriza la fase del capitalismo actual (21). 
haya sido rechazado (Cherki 18). Más adelante, en la introducción, Fanon hace explícita su operación política cuando escribe que, como adelantamos, aunque el análisis es psicológico,

la verdadera desalienación del negro implica una toma de conciencia abrupta de las realidades económicas y sociales. El complejo de inferioridad se deriva de un doble proceso: -Económico, en primer lugar.

-Por inferiorización o, mejor, epidermización de esta inferioridad, después (10).

$\mathrm{Al}$ adoptar un lenguaje cargado de subjetivemas, en algunas instancias violento, incluso bélico, bien alejado de la anhelada objetividad e imparcialidad de la ciencia, Fanon asume una escritura descolonizadora respecto de los parámetros disciplinares aprendidos y los modelos culturales heredados. Su objetivo es impulsar un cambio social, revolucionario, concreto: "Estimamos que, a causa de la presencia de las razas blanca y negra, hay un complejo masivo psico-existencial. Al analizarlo apuntamos a su destrucción” (12). El psiquiatra rehúsa, con extrema ironía, el método científico: "En una obra de psicología es de buen gusto avanzar un punto de vista metodológico. Renunciamos a la costumbre. Dejamos los métodos a los botánicos y a los matemáticos. Hay un momento en que los métodos se reabsorben" (Fanon 11).

Antes que la mera exposición de conocimiento, prevalece la voluntad de persuadir respecto de la visión comunitaria del mundo, un mundo en el cual "la relación negro-blanco" (8) se vuelve fundamental para el autor. Pero " $[y]$ a no se trata de conocer el mundo, jsino de transformarlo!" (14), anuncia Fanon de modo radical; y, en tal sentido, Piel negra, máscaras blancas comparte los rasgos que la crítica Liliana Weinberg encuentra de modo marcado en el ensayo latinoamericano, entendido este no como ejercicio gratuito y neutral sino como "puesta en valor" y examen "desde el mirador del compromiso" (103).

El ensayo en América Latina -una tradición literaria surgida, como el ensayo antillano, bajo situaciones de dependencia- se caracteriza para Weinberg por la tematización de las diversas "condiciones de inteligibilidad". El ensayista es un "héroe atenaceado entre la voluntad de universalidad y la necesidad de atender a los diversos amarres que lo atan a un tiempo, a un espacio, a una visión del hombre que nos fueron 
heredados y han de ser asimilados, discutidos, rebatidos: interpretados" (59). Cuando se trata, además, de la ensayística desde y sobre la región, se debe ańadir a las condiciones de inteligibilidad respecto de un campo específico y de la cultura en general el problema de las "condiciones exteriores ligadas a ese constructo imaginario que llamamos 'cultura occidental'” (Weinberg 60), condiciones de inteligibilidad regidas extraterritorialmente, de modo colonial. La ubicación del autor en tiempo y espacio, las condiciones sociales, políticas, económicas y culturales son determinantes en un autor afrodescendiente afiliado al marxismo y que, además, reconoce la urgencia de atender a las singularidades de los países coloniales. Así, por ejemplo, Fanon -quien en el mismo ensayo se presenta como "antillano de origen" cuyas "observaciones y conclusiones solo valen para las Antillas" (13) - discutirá el "universalismo" de Jung al sentenciar que "el inconsciente colectivo no es herencia cerebral" sino adquirida, la consecuencia de la "imposición cultural irreflexionada" $(158)^{13}$. En consecuencia, puesto que el inconsciente colectivo de Europa es racista, y dado que Martinica es un país europeo por su inconsciente colectivo, se vuelve imperioso trabajar sobre la psiquis martiniqueña: "Es urgente desembarazarse de toda una serie de taras y secuelas del periodo infantil", explica Fanon en la introducción (10).

Si la modulación pedagógica del ensayo de Fanon es efecto de un estilo por momentos dialógico, en el que predominan preguntas y respuestas que facilitan el didactismo en pos de una consecuente toma de conciencia, también resulta decisiva la exposición de casos clínicos tal como lo dispone la disciplina. Pero en Piel negra, máscaras blancas abundan los relatos literarios -ficticios aunque verosímiles-, puesto que, como el mismo autor explicita, el objetivo es "permitir al hombre de color comprender, con ayuda de ejemplos concretos, los factores, los ingredientes psicológicos que pueden alienar a sus congéneres" (Fanon 65).

De modo significativo, a través del desarrollo de ejemplos, desde el capítulo dedicado a "El Negro y su lenguaje", emerge en el ensayo un patrón narrativo - literario- que se abastece con un claro fin pedagógico del modelo del Bildungsroman occidental. La trama psicológica favorece, así, la autoidentificación del lector a quien Fanon se dirige, pues

13 La crítica de Fanon al etnocentrismo (y falso universalismo) de la psicología europea es explícita en el ensayo: "Ni Freud ni Adler, ni siquiera el cósmico Jung pensaron en los negros al realizar sus investigaciones" (125-126). 
se presta a una fácil decodificación a partir del conocido esquema del protagonista en vía de formación, heredero del héroe épico, que parte de su lugar natal a completar su educación en el mundo exterior -el viaje como aprendizaje-, y cuya emancipación se cumple cuando logra su inserción plena en la sociedad. Con sumo sarcasmo, Fanon deconstruye la formación colonial de los antillanos, lo que sería el modelo de Bildung para el migrante negro: el dominio de la lengua francesa como símbolo de la asimilación lograda, la conquista de París como cima del éxito alcanzado, la realización -que solo puede encontrarse en la metrópolis- entendida como blanqueamiento:

El negro que entra en Francia cambia porque, para él, la metrópoli representa el Tabernáculo; cambia, no solamente porque es de este país de donde le llegaron Montesquieu, Rousseau y Voltaire, sino porque también de él llegan los médicos, los jefes de servicio, los innumerables pequeños potentados [...]. Hay una especie de embrujamiento a distancia, y quien va a partir dentro de una semana con destino a la Metrópoli, crea a su alrededor un halo mágico en el que las palabras París, Marsella, La Sorbona, Pigalle, representan las llaves de la bóveda. El negro parte, y la amputación de su ser desaparece a medida que se precisa el perfil del paquebote (Fanon 19).

Por supuesto que esta teleología del viaje según la cual el sujeto colonial se completaría culturalmente en Europa solo puede entenderse como un proceso de "mixtificación", una "lactificación que es alucinación” (Fanon 82) y que producirá en los inmigrantes a la metrópolis, en lugar del logro de autonomía, una profunda alienación. En el quinto capítulo, "La experiencia vivida del negro", Fanon asume una primera persona para su racconto ejemplar que viene a cerrar el esquema narrativo planteado. Diseńa una suerte de autobiografía intelectual ficticia pero representativa de lo que constituye para el colonizado una Bildung fallida, puesto que, en la metrópolis, lo primero que escucha el negro es:

“ $¡$ Cochino negro!” o, simplemente, “iMira, un negro!”. Yo llegaba al mundo ansioso de encontrar un sentido a las cosas, mi alma henchida del deseo de estar en el origen del mundo, y hete aquí que yo me descubría objeto en medio de otros objetos (Fanon 90). 
$\mathrm{Si}$, según los patrones narrativos europeos que dieran expresión a los ideales iluministas, entendemos la realización de una Bildung como la conquista de una conciencia autónoma que permite la realización del sujeto en la sociedad, la imposibilidad del negro de alcanzarla es atribuida por Fanon a una psicopatología propia de las colonias, que evoca la "desviación patológica" percibida ya por Price-Mars, y que es producto de la cultura negrófoba europea impuesta desde las metrópolis y "asimilada" por los colonizados.

A diferencia de lo que sucede en Europa, donde la familia y la nación mantienen una correlación, y donde la autoridad del Estado reproduce la autoridad familiar -"El niño que sale del medio parental descubre a continuación las mismas leyes, iguales principios, idénticos valores. [...] No existe desproporción entre la vida familiar y la nacional" (Fanon 118)-, en las Antillas existe una total disyunción entre la familia y la estructura nacional -francesa, europea-. El niño negro, prosigue Fanon, se ve obligado a escoger entre su medio familiar y la sociedad europea y, dada su educación negrófoba, "tiende a rechazar la familia -la negra, la salvaje- en el plano de lo imaginario" y a comportarse como un niño blanco (124). El problema surge al enfrentar de modo consciente su situación en cuanto migrante negro, al no ser reconocido como sujeto entre los blancos. No se trata, aclara el psiquiatra martiniqueño, de la mera adaptación a lo social -el criterio de la virilidad que, a la sazón, es tematizado por el patriarcal modelo del Bildungsroman- sino que el negro afronta en la metrópolis el mito racial -y el racismo-, ignorado mientras vivía entre los suyos en las Antillas. Educado -aculturado- en la colonia a través de historias, cuentos, revistas ilustradas, carteles, cine, radio, que constituyen una visión de mundo blanca donde "El Lobo, el Diablo, el Genio Maligno, el Mal, el Salvaje se representan siempre mediante un negro o un indio..." (119); acostumbrado a repetir en la escuela "nuestros padres los galos", como también recuerda Fanon, y a identificarse "con el explorador, el civilizador, el blanco, que es quien trae la verdad completamente blanca" (122), el negro descubre en Europa su inadecuación social, su inferioridad, su alienación.

Contra la pedagogía racista y colonial determinante de la psicopatología del negro, y a sabiendas de lo contradictorio que resulta para el psiquiatra "proponer una solución a un semejante, es decir, a una libertad" (51), la vía más accesible - puesto que la verdadera revolución 
en las Antillas se le muestra a Fanon lejana- parece ser la educación: "Ni más ni menos, crear revistas ilustradas destinadas especialmente a los negros, canciones para los nińos negros y, en el límite, obras de historia, al menos hasta la obtención del certificado de estudios" (123). $\mathrm{Al}$ igual que Price-Mars, quien atribuye el problema a que el haitiano culto "se sirve de una lengua prestada -el francés-, porque nutre su pensamiento con obras francesas", y quien reivindica el folklore local para el desarrollo de una literatura "indígena" (Price-Mars 238), Fanon asigna a la pedagogía antirracista un decisivo papel descolonizador.

\section{Conclusiones}

Cuando Frantz Fanon escribe Piel negra, máscaras blancas, con la excepción de algunos poetas como Aimé Césaire-cuyo Cuaderno de un retorno al país natal (1939) se erige en el ensayo como una verdadera paideia descolonizadora-, no existe en las Antillas aún francesas "expresión negra" (126), y resulta imperioso el desarrollo de un programa formativo descolonizador, entendido por Fanon de modo radical: no como intercambio o negociación armónica, sino como profundo desaprendizaje de las ideas, creencias y valores hegemónicos "blancos" que han sostenido la misma construcción del negro.

Mientras las nociones de mestizaje, criollización e interculturación, o el concepto de "transculturación" del cubano Fernando Ortiz, como sabemos, han sido dominantes en el discurso teórico sobre la identidad caribeña -en el caso de Price-Mars, la propuesta es "indigenizar" la cultura y la lengua francesas-, el posicionamiento de Fanon es extremo: la descolonización significa una ruptura total con la autoridad blanca y con el concepto mismo de cultura occidental.

Las paradojas, por supuesto, afloran cuando reflexionamos que Fanon no solo escribe en francés -en lugar del créole entonces considerado incapaz de devenir lengua escrita ${ }^{14}-$, sino que acude además al ensayo

14 En el capítulo "El Negro y su lenguaje", Fanon incluso critica el rechazo del créole, considerado una lengua vergonzante: "La burguesía de las Antillas no emplea el criollo, salvo en sus relaciones con los domésticos. En la escuela el joven martiniqués aprende a despreciar el patois [...]" (16). Fanon cita, luego, 
como género "didáctico". Si bien, como hemos observado, la ensayística en los autores antillanos -Price-Mars, Césaire, Fanon, y tantos otros más del Caribe multilingüe-adquiere una modulación política evidente, relacionada con el compromiso social de los intelectuales y la urgencia por desarrollar programas nacionalistas/descolonizadores -que determinan el desborde de sus campos disciplinares-, pervive en Fanon la confianza en los métodos pedagógicos heredados y en la misma lengua francesa como vehículo de descolonización mental. Para Price-Mars, en efecto, era posible "indigenizar" el francés, ya que la lengua "no crea el pensamiento mismo y tampoco es su modo exclusivo de expresión" (238). Fanon, cual Calibán, usará la lengua colonial para maldecir, proponiendo una ruptura total con los libros occidentales, aunque se trate, más bien, de servirse de ellos para descultivar el racismo y desepidermizar las desigualdades económicas y sociales. El despojo del negro del color que lo ha habitado desde niño mientras fuera educado bajo los ideales abstractos de la Revolución francesa restituye, para Fanon, la soberanía perdida, e implica descolonizar hasta el mismo concepto heredado, liberal, de libertad.

\section{BiBLIOGRAFÍA}

CÉsaire, Aimé. “Juventud negra y asimilación”. Katatay. Revista crítica de literatura latinoamericana, No 11-12, 2014, pp. 101-102.

Cherki, Alice. Frantz Fanon. A Portrait. Nueva York, Cornell University Press, 1975.

Depestre, René. "Prólogo". Así habló el tío, Jean Price-Mars, La Habana, Casa de las Américas, 1968, pp. IX-XXXI.

Fanon, Frantz. Piel negra, máscaras blancas. Buenos Aires, Editorial Abraxas, 1973.

Groussac, Paul. Del Plata al Niágara. Buenos Aires, Jesús Menéndez, 1925.

un pasaje del maravilloso poema "Hoquet" del guyanés L. G. Damas (Pigments, 1939), en el cual se lee: "Vous ai-je dit ou non qu'il vous fallait parler français/ le français de France/ le français du français/ le français français [...]" ("Cállate, te he dicho que tenías que hablar francés/ el francés de Francia/ el francés del francés/ el francés francés" (Fanon 17). 
Malela, Buata B. Les écrivains afro-antillais à Paris (1920-1960): stratégies et postures identitaires. París, Karthala, 2008.

Novau, Julieta. "Nomadismos del decir: avatares de la identidad afroantillana en Así habló el tío de Jean Price-Mars y El reino de este mundo de Alejo Carpentier". Orbis Tertius. Revista de Teoría y Critica Literaria, vol. 12, N 13, 2007. Web. Disponible en: www. orbistertius.unlp.edu.ar/article/view/OTv12n13a05

Price-Mars, Jean. Asi habló el tío. La Habana, Casa de lasAméricas, 1968.

Sharpley-Whiting, Tracy Denean. "Femme négritude. Jane Nardal, La Dépêche africaine, and the Francophone New Negro". Souls, vol. 2, N4, 2000, pp. 8-17.

Segato, Rita. La guerra contra las mujeres. Madrid, Traficantes de sueños, 2016.

Segura Munguía, Santiago. Lexicón [incompleto] etimológico y semántico del Latín y de las voces actuales que proceden de raíces latinas o griegas. Bilbao, Universidad de Deusto, 2014.

Weinberg, Liliana. El ensayo, entre el paraíso y el infierno. Ciudad de México, UNAM-FCE, 2001.

Williams, Raymond. Keywords. A Vocabulary of Language and Culture. Nueva York, Oxford UP, 1983.

Recepción: 22-05-2020

Aceptación: 12-01-21 